\title{
Mahnur Jafarli \\ Sorption from aqueous solutions of non-ferrous metal ions with dowex M 4195 ionite
}

Institute of Natural Resourses

(Azerbaijan, Nakhchivan branch)

doi:10.18411/spc-12-02-2018-04

idsp: 000001:spc-12-02-2018-04

This report presents the results of equilibrium, kinetics, thermodynamics and desorption of sorption $\mathrm{Cu}^{2+}, \mathrm{Co}^{2+}, \mathrm{Ni}^{2+}$ ions Dowex M-4195 (bis-picolylamine functional group) in the sulfuric acid salt form cationites. The change of parameters, such as energy and entropy of activation, free energy of sorption and diffusion coefficients change on various factors. Thermodynamic description of exchange of studied ions by exchangers was conducted on the assumption of ideality of the solid phase, i.e, without taking into account the activity coefficients of ions in the absorbed state. Analysis of the kinetic curves methods by G.Boyd, Yu.A.Kokotov and V.A.Pasechnik and interruption methods revealed that at a concentration of about $1.0 \mathrm{~g}$ of sorbates $\mathrm{E} \cdot \mathrm{L}^{-1}$ is controlled intradiffusion kinetics. The value of the entropy of activation was calculated from the equation proposed by R.M.Barrer and his collaborators: $\mathrm{D}_{0}=\mathrm{d}^{2}(\mathrm{ekT} / \mathrm{h}) \exp \left(\Delta \mathrm{S}^{*} / \mathrm{R}\right)$.

By results of a desorption it is shown more efficiency 3-6\% -s solution thiourea in a solution 0.1-0.2 $\mathrm{n}$ hydrochloric acid. Desorption of $\mathrm{Cu}^{2+}$ ion is more effective than desorption of $\mathrm{Co}^{2+}$ and $\mathrm{Ni}^{2+}$ ions. The sharp peak in desorption curves is indicates that this regeneration more effective. when peak vaguely it is appears ineffectively of desorption and that more desorbent consumed than required.

It is shown that curves sorption submit to an isotherm of Langmuir. Sorption of ions across the study area on the consentrations of these ion exchangers primarily occurs by the mechanizm of Langmuir, i.e. ion exchangers is formed on the sur-face of a monomolekulyar layer and a sorption all active senters are mainly of equal energy and enthalpy of absorption. We offer relevant equations describing isotherms similar to the equations of Langmuir.

Kinetic studies have shown that the sorption equilibrium when removing the metal ions is well established within 2.5-3.0 hours. After interruption, it was that there was an increase observed in the speed of sorption in all three ions. This law is characteristic for gel kinetics. In this case, the rate of sorption depends on the ions diffusion of the ionic phase. Another indicator of the internal diffusion is the linear characteristic of $\mathrm{F}-\sqrt{\mathrm{t}}$ dependence in saturation rate up to about $0.4-0.5$. In the systems we operate, $F-V_{t}$ dependency is linear character for about 50 minutes from the beginning of the sorption. This form of analysis, the dependence is typical for ion exchange processes, the kinetics of which is determined by the internal diffusion.

In the experiments conducted for the calculation of thermodynamic quantities, $\mathrm{C}_{0}=0.5 \mathrm{~g} \mathrm{E} \cdot \mathrm{L}^{-1}$ from concentration solutions were used the values of the change constant was also selected for this consentration.

In all three proceses dependence of separation of heat and decrease of entropy during the change of the less selective ion into the more selective ion on the enthalpy factor of selectivity has been prevails. Selectivity is manages by the enthalpy factor. The values obtained for the thermodynamic quantities confirm that the processes can take place spontaneously at room temperature, about the results of the actual speeds of processes are also confirmed. One of the most important theoretical and practical results of this work is the proof of the relationship of selective sorption and kinetic ion exchanger capacity: increase of the kinetic constant of ion exchangers is accompanied by increased selectivity of sorption. Hibbs energy studied by us in all cases is and minimal for protonated forms of ion exchangers.

Kinetic and thermodynamic parameters of sorption of $\mathrm{Cu} 2+, \mathrm{Co} 2+$ and $\mathrm{Ni} 2+-$ ions with Dowex M 4195 resin.

\begin{tabular}{|c|c|c|c|c|c|c|c|c|}
\hline & $\mathrm{D} \mathrm{sm}^{2} / \mathrm{sec}$ & $\mathrm{D}_{0} \mathrm{sm}^{2} / \mathrm{sec}$ & $\begin{array}{c}\text { Eakt } \\
\mathrm{KJ} / \mathrm{mol}\end{array}$ & $\begin{array}{c}\Delta \mathrm{S} \\
\mathrm{J} / \mathrm{mol} \cdot \mathrm{K}\end{array}$ & $\begin{array}{c}\Delta \mathrm{H} \\
\mathrm{KJ} / \mathrm{mol}\end{array}$ & $\begin{array}{c}\Delta \mathrm{G} \\
\mathrm{KJ} / \mathrm{mol}\end{array}$ & $\mathrm{K}^{\prime}$ & $\mathrm{C}_{0} \cdot \mathrm{gE} / \mathrm{L}$ \\
\hline $\mathrm{Cu}^{2+}$ & $1.15 \cdot 10^{-7}$ & $1.88 \cdot 10^{-4}$ & 18.50 & -45.02 & -10.95 & -2.46 & 2.70 & 0.5 \\
\hline $\mathrm{Co}^{2+}$ & $1.60 \cdot 10^{-8}$ & $6.75 \cdot 10^{-4}$ & 26.4 & -34.39 & -8.02 & -2.23 & 2.46 & 0.5 \\
\hline $\mathrm{Ni}^{2+}$ & $1.85 \cdot 10^{-8}$ & $3.65 \cdot 10^{-4}$ & 24.5 & -39.50 & -9.64 & -2.13 & 2.36 & 0.5 \\
\hline
\end{tabular}

